\title{
Ethnobotany and Ethnopharmacology, the First Step towards Bioprospecting
}

\author{
Isabel Martínez-Solís*
}

Department of Pharmacy and Biomedical Sciences Research Institute, CEU Cardenal Herrera University, Valencia (Spain)

*Corresponding author: Isabel Martínez-Solís, Coordinator Head Researcher of SEPLAN, Universidad CEU Cardenal Herrera, Faculty of Health, Department of Pharmacy, Building Seminar s / n. 46113 Moncada (Valencia) Spain, Tel: 9613690 00; E-mail: isolis@uch.ceu.es

Received date: Dec 12, 2014, Accepted date: Dec 16, 2014, Publication date: Dec 19, 2014

Copyright: (c) 2014 Solís IM. This is an open-access article distributed under the terms of the Creative Commons Attribution License, which permits unrestricted use,distribution, and reproduction in any medium, provided the original author and source are credited.

\section{Editorial}

The Journal of Biodiversity, Bioprospecting and Development is a good context to evaluate from a scientific point of view the importance of biodiversity and its use and effects on social development, including economic development. Humans have always used natural resources because they are part of the environment and inevitably interact with it. Foods, medicines, home all have their origin in nature. In the evolutionary process of human society, the use of natural resources based on direct experience became a use based first on cultural tradition, and later on scientific research and evidence. It is important to understand the role of 'ethno' sciences and other social sciences for the development of human societies, as well as the significance of science, which is reflected in scientific publications. The conflict of interests between various parties involved in bioprospecting has already started, and social actors have a relevant role because ethno sciences are involved. We present the problem in this editorial article, in the best framework: this journal.

Although the concept of bioprospecting is relatively new, in practice it is an ancient activity that began when humans began to use natural resources. This concept is related with finding biochemical and genetic resources that have business value, and it is based on scientific research, biodiversity analysis and popular culture. Resources were initially identified through experience and classified as medicine, food, poison and glue for hunting, hallucinogen or "spiritual" substance, etc. Experience, information and their interrelationship favoured the development of popular culture and natural resource use. According to this ancient origin of bioprospecting, aspects related to Botany, Anthropology, Archaeology, Phytochemistry, Pharmacy, History, Geography, Ecology and other art and science fields will be taken into account. These are sciences that are included in Ethnobotany and Ethnopharmacology, and in fact may be considered the origin of modern bioprospectors because have contributed to the discovery of many important plant drugs, enabling bioprospecting implementation. Ethnobotanists perform research on uses and concepts of plants in cultures and societies (popular knowledge), and Ethnopharmacologists research the medicinal uses of plants and their properties from popular culture data. Ethnobotany has now evolved into a much broader concept that includes not only a utilitarian relationship, but also embraces other ecological and cognitive concepts, as well as the human-plant relationship in a modern framework. According to the International Society of Ethnopharmacology Constitution (2005) [1], Ethnopharmacology has also undergone an evolution from the classic to modern concept, but changes are lighter than those suffered by Ethnobotany. First it was understood as a multi-disciplinary field of research that concerns observation, description and experimental investigation of indigenous drugs and their biological activities. The definition now includes the interdisciplinary study of the physiological actions of plants and other organisms or substances that were used in past indigenous medicines and are now used in present cultures. Modern ethnopharmacology embraces botanical, ethnobotanical, phytochemical, ethnopharmacological, pharmacological and toxicological fields.

Ethnobotany and Ethnopharmacology, like all ethno sciences, have in common a human and cultural component. A new term later arises, Bioprospecting. This concept includes biodiversity information, cultural information and obtaining business value products. Thus when purpose and outcome from ethno sciences, experimental and basic sciences, and technology are commercial in nature the activity is known today as bioprospecting. This term is also applied to the exploration and utilization of biological diversity itself for commercial purposes. Bioprospecting was initially considered justified and a winwin situation because the outcome benefited the scientific community and society as a whole. In the previous decades the new science has gained prominence due to technological advances in pharmaceutical, biotechnological and agricultural sectors. Thereafter a conflict of interest arose due to the poor distribution of economic benefits provided by natural resources and the damage that over-exploitation may do to the environment. Soejarto et al. [2] explain this situation and show several examples. They consider that multidisciplinary research is necessary due to the broad spectrum of requirements that must be taken into account: scientific expertise in all necessary disciplines, participation of indigenous peoples, adoption of modern culture, and a wide range of human endeavours, including diplomacy, international laws and legal understandings, social sciences, politics, anthropology and very important, common sense.

Apparently, only a low percentage of plants have been scientifically researched to assess their medicinal and pharmaceutical potential, and the number of researched plants with other uses is lower. Therefore plants continue to represent a significant source of raw material for the discovery of new drugs or substances with other uses and always of business value. In fact, discoveries of novel molecules and advances in production of plant-based products have revived interest in natural product research [3]. These new discoveries derive from traditional knowledge that has proven a useful tool in the search for new plantbased medicines. Consequently the world's biodiversity and ethnobotanical and ethnopharmacological knowledge will continue to present an attractive target for future bioprospecting efforts. In this context, the activity of multidisciplinary research groups is necessary, as well as the publication of research results, as this is the first step towards bioprospecting. But it must be remembered that investigation alone is insufficient. In order to avoid conflict of interest, an international agreement that includes issues concerning access to the genetic resources and equitable sharing of benefits is necessary, and therefore must also be respected by all bioprospectors. Furthermore, conservation and protection of the biological resources for the future generations must also be taken into account. 
Citation: Solís IM (2014) Ethnobotany and Ethnopharmacology, the First Step towards Bioprospecting. J Biodivers Biopros Dev 2: e107. doi: 10.4172/2376-0214.1000e107

Page 2 of 2

In short, Bioprospecting ensures future medicines and other substances that provide social and economic progress, and Ethnobotany and Ethnopharmacology are the essential starter, in the context of sustainable development and honest sharing of the benefits derived from exploitation of natural resources such as plants. This formula, as I see it, will be beneficial for rational bioprospecting that may provide sanitary, social and economic development in the world society as a whole. Your opinion is now necessary given the controversy created, as you too are an actor in bioprospecting and it affects you.

\section{References}

1. http://guallart.dac.uga.edu/ISE/iseConstitution.html.

2. Soejarto DD, Fong HH, Tan GT, Zhang HJ, Ma CY, et al. (2005) Ethnobotany/ethnopharmacology and mass bioprospecting: issues on intellectual property and benefit-sharing. J Ethnopharmacol 100: 15-22.

3. Saslis-Lagoudakis CH, Savolainen V, Williamson EM, Forest F, Wagstaff SJ, et al. (2012) Phylogenies reveal predictive power of traditional medicine in bioprospecting. Proc Natl Acad Sci U S A 109: 15835-40. 